\title{
Memórias do feminismo: repressão e invisibilidade (Brasil e Argentina pós-1968)*
}

\author{
Ana Maria Veiga**
}

O ano de $\mathbf{2 0 0 8}$ marca as quatro décadas do emblemático 1968, quando manifestações políticas e culturais eclodiram em várias partes do mundo, influenciando decisivamente as gerações que se seguiram a partir dali. Os ecos destas manifestações acabaram por levantar uma grande onda, que tiraria da estagnação um grupo até então visto como pouco importante nas sociedades ao redor do mundo, fazendo emergir a partir dele um novo sujeito social e político: as mulheres.

Se hoje pensamos e discutimos questões que envolvem o gênero e a desigualdade - culturalmente construída, é sempre bom lembrar - ainda latente entre os dois sexos da espécie humana, é porque tivemos um impulso motor com as feministas da segunda onda, ${ }^{1}$ com seu auge nos anos 1970.

No Brasil, vários nomes despontam no cenário das reivindicações por igualdade, mesmo sem a identificação imediata com o feminismo termo considerado então como ofensa ou xingamento proferidos pelo desejo de invalidar os protestos das mulheres que não iriam mais se calar. Elas seriam então as "feias", "lésbicas" e "mal-amadas" que, sem a proteção

\footnotetext{
* Este trabalho, orientado pela Prof ${ }^{a}$ Dra. Joana Maria Pedro, da Universidade Federal de Santa Catarina, faz parte do projeto Movimento de mulheres e feminismos em tempos de ditadura militar no Cone Sul (19641989), financiado pelo CNPq e coordenado pela mesma.

** Mestranda da Universidade Federal de Santa Catarina.

1 Quando dizemos segunda onda do feminismo, partimos da referência das manifestações pelo voto com as chamadas sufragistas, no início do século XX, como a primeira onda.
} 
e o interesse dos homens, saíam às ruas para gerar desordem e gritar palavras sem sentido algum para uma sociedade hierarquizada pelo gênero, sob o domínio masculino.

Heleieth, Moema, Maria Lygia, Danda, Santinha, Maria Odila, Albertina, Zuleika, Heloneida... tantas outras que fizeram história e, mais que isso, semearam consciência também para outras mulheres, numa grande rede que se emaranhou em outros fios, para além das fronteiras nacionais. Ao olharmos para a vizinha Argentina, encontramos lá outras protagonistas: Mirta, Sara, Leonor, Dora, Blanca, María Elena, Lucrecia... Brasileiras e argentinas poderiam não ter nada em comum, não fosse a mesma luta pela igualdade, que ganha especificidade no contexto mais amplo das ditaduras militares que varreram os países sul-americanos nesse mesmo período.

Além da descoberta de uma mesma necessidade, trabalhada com as ferramentas forjadas pelo feminismo, um cenário obscuro e conturbado por ameaças e incertezas completou o quadro de um delicado momento nas vidas dessas mulheres.

Movida pelo interesse em ver mais de perto como se davam as relações entre elas e a rede de circulação de informações e teorias que se criava com a leitura de materiais nacionais e estrangeiros e a publicação de discursos sobre temas semelhantes, busquei, nos depoimentos de feministas brasileiras e argentinas que protagonizaram esses primeiros anos, ${ }^{2}$ elementos para pensar o feminismo como movimento, nas suas continuidades e rupturas.

Permeadas pelo violento contexto militarizado/masculinizado que se estendeu pela América do Sul durante três décadas, feministas brasileiras e argentinas traçavam estratégias para que sua causa sobrevivesse, para além daquele momento e da bandeira de uma luta mais geral contra os governos da direita, legitimada no poder pelos golpes que assolaram praticamente toda a região.

O período aqui proposto vai de 1968 até o final da década de 70, partindo de pontos de convergência, mas também de distanciamento entre os dois países em questão. Afinal, quais as semelhanças e as diferenças na

2 As entrevistas analisadas foram realizadas como parte de uma pesquisa maior intitulada Feminismos e os movimentos sociais de resistência às ditaduras no Cone Sul: uma história comparativa (1960-1985), organizado e conduzido por Joana Maria Pedro, Cristina Scheibe Wolff, Roselane Neckel e Marcos Freyre Montysuma, da Universidade Federal de Santa Catarina, na área de História. 
constituição dos feminismos no Brasil e na Argentina? Como se constituiu esse novo sujeito político e qual a sua representatividade social nos dois países?

Pretendo me acercar de respostas possíveis para estas questões com o suporte da história oral, representado aqui por Alessandro Portelli (1998), Verena Alberti (2005), Silvia Salvatici (2005), e o aparato das discussões sobre identidade e identificação propostas por Stuart Hall (2000).

Minhas fontes são entrevistas realizadas com as feministas brasileiras Heleieth Safiotti, Maria Lygia Quartim de Moraes, Moema Toscano, Maria do Espírito Santo Tavares dos Santos (Santinha) e Yolanda (Danda) Prado; e com as argentinas Mirta Henault, Sara Torres, Leonor Calvera, além da autobiografia de María Elena Oddone (2001).

Como rememoração de uma semente lançada há exatos quarenta anos, proponho uma pausa para "ouvirmos" o que têm a dizer estas protagonistas do movimento feminista e perceber como seus discursos se aproximam e se afastam, traçando diversas possibilidades para as estratégias feministas e deixando vazar seus pontos de ruptura e divergência, assim como esquecimentos, omissões e contradições que fazem parte da documentação erigida sobre testemunhos orais.

Como objetivo principal deste artigo, pretendo analisar, nos discursos das protagonistas do movimento feminista da segunda onda no Brasil e na Argentina, como se davam as relações entre elas, as semelhanças e as diferenças nas estratégias criadas e a formação de uma rede de circulação de discursos e teorias entre os dois países - considerados periféricos -, formando uma triangulação com os pontos geográficos centrais - Europa e Estados Unidos.

Além disso, busco observar o "movimento feminista" como a junção de fragmentos de ações e estratégias diversas; analisar quais influências tiveram na constituição de uma subjetividade política e social, partindo principalmente da condição das mulheres políticas que militavam nos partidos de esquerda contra as ditaduras militares; pretendo também observar o papel que essas mulheres ocupavam no contexto da repressão, já que muitas foram perseguidas e exiladas; avaliar as contribuições dos testemunhos orais, que devem ser analisados de maneira crítica, considerando a validade da abrangência de pontos de vista diferentes, e também suas contradições; e, por fim, proponho o entendimento desses testemunhos como uma abertura de possibilidades para a historiografia do tempo presente. 


\section{Entre testemunhos e história}

Optei por trabalhar com entrevistas no sentido de abrir maiores possibilidades de compreensão de como se estendeu essa rede feminista de circulação de discursos e teorias entre os dois maiores países da América do Sul, governados pela direita militarizada, em diferentes períodos (o Brasil de 1964 a 1985 e a Argentina de 1976 a 1983), mas que apresentam histórias semelhantes em vários aspectos.

Quando o material disponível para uma pesquisa histórica é constituído de depoimentos, sejam eles orais ou escritos, a primeira questão que se apresenta é a importância desse material para o trabalho historiográfico e, dentro dele, quais os pontos mais relevantes para análise, crítica e compreensão. $\mathrm{Na}$ sobreposição constante do passado ao tempo presente e também a via inversa, nos silêncios, nas falas ressentidas, nas comparações e auto-afirmações, os discursos se apresentam e se preenchem como um todo. O todo possível, o lembrado, o escolhido. Um caminho possível é transitar entre a racionalidade individual e a identificação coletiva, inscrevendo essas memórias no contexto das relações sociais.

Tomo as entrevistas como discursos simultâneos - no passado e também no presente - de mulheres que viveram e atuaram no campo do feminismo e na resistência aos regimes militares. A posição de cada uma delas e as relações com as demais companheiras variam de acordo com a alternância dos pontos de vista, voltados para si, para as outras e para os grupos.

Procurei estar atenta às "falhas" da memória, às emoções que permeiam os depoimentos, aos rancores e às intenções que movem as escolhas daquilo que se vai dizer no "falar de si".

Quanto às três entrevistas com as feministas argentinas, elas foram realizadas por mim entre fevereiro e março de 2007, portanto trago na memória aquilo que ouvi e gravei, mas também os olhos brilhantes e saudosos daqueles tempos vividos sobretudo com paixão.

A militância e os discursos escritos são o legado dessas mulheres para uma história que teima em apagar seus registros. Por meu lado, o que busquei foi trazê-los à tona mais uma vez, tentar entender com olhos do presente o que significou a contribuição das mulheres que militavam no feminismo dos anos 1970 para a continuidade das reivindicações atuais.

Analisei criticamente cada depoimento sob vários aspectos, desde o fator social de cada uma delas, seu país de origem, a posição política no 
período, a militância de ação ou intelectual, o direcionamento do discurso, o falar de si... Cada ponto colocado em relação com os outros, na busca de histórias possíveis, de discursos situados dentro de um contexto, ao lado de outros discursos, todos plenos de intenção.

A leitura da autobiografia de María Elena Oddone, uma passada de olhos pelo material feminista que ela, além de outras, publicava, a busca dos aparatos teóricos que podem ajudar a apreender o sentido desses discursos, completaram a metodologia deste trabalho, que se pretende apenas uma peça de um grande quebra-cabeça que busca compreender melhor a história dessas mulheres que movimentaram aqueles anos da segunda onda, considerados embrionários para as mudanças sociais e políticas que se seguiram.

\section{Vozes do feminismo no contexto da repressão}

Vamos começar por Heleieth Saffioti, que não se considerava feminista. Nascida em família pobre, a identificação primeira se deu com o marxismo, com o qual acabou por inserir o tema da "mulher" na luta de classes, num livro escrito em 1966 e publicado em 1969 (Saffioti, 1979). Heleieth foi pioneira, dentro e fora do Brasil. Com o passar do tempo, a convergência com o feminismo se tornou inevitável e hoje ela é um dos ícones do movimento no país, ou talvez um marco fundante para as feministas da segunda onda.

[...] eu tomei consciência que eu tinha que assumir, mesmo que eu tivesse que explicar em todos os lugares que o meu feminismo não tinha nada a ver com o feminismo radical americano, que queria uma sociedade só de mulheres, e era o que eu fazia, explicava sempre, era terrível ser tachada de feminista, que aí era sapatão na hora, era a primeira coisa que acontecia (Entrevista com Heleieth Saffioti). ${ }^{3}$

3 Informações complementares sobre as entrevistas encontram-se ao final do artigo. 
A associação de um "rótulo" vinculado à sexualidade - no caso à homossexualidade - com o feminismo, acabou por reprimir a adesão de muitas mulheres à luta aberta pela igualdade e era usado como argumento final por uma sociedade falocrática, no sentido de invalidar essas idéias consideradas pouco importantes ou irrelevantes, que questionavam valores sociais completamente estabelecidos. De acordo com Joana Maria Pedro (2006),

Durante muito tempo ser feminista foi considerado como sinônimo de ser feia, mal-amada, masculinizada e ressentida. Jornais do início do século XX, na primeira onda feminista, eram enfáticos em afirmar tal coisa. A palavra "feminismo" esteve por muito tempo - e talvez até os dias de hoje - cercada de conotações desqualificantes.

Em terras argentinas encontramos uma outra mulher política: Mirta Henault. Trotskista convicta, ela foi perceber melhor o preconceito que superava a questão de classe dentro da esquerda argentina. Em 1970 escreve e publica, com mais duas companheiras, Las Mujeres dicen Basta (Henault et. Al., 1970), o primeiro livro que propõe essa temática em seu país. Mirta aos poucos percebe que as questões de gênero e o preconceito não eram irrelevantes, como pregavam os partidos (de direita ou de esquerda), mas estavam acima da luta de classes, como pano de fundo, tornando perene uma situação que começa a ser percebida e contestada pelas primeiras feministas desse período.

Maria Lygia Quartim de Moraes confirma que, para mulheres políticas como ela, a luta política era mais importante que o feminismo. Sua família não enfrentou problemas financeiros, portanto pôde viver no Chile de 1971 até o momento do golpe, em 1973, quando foi para Paris, sempre convivendo com exiladas de diversos países. Para ela também não foi tarefa fácil se assumir feminista. Quando voltou ao Brasil em 1975, engajouse ao grupo que publicava o periódico Nós Mulheres. Ela conta que Nós Mulheres deixou de ser uma publicação em 1979, mas as componentes do grupo continuaram a atuar, formando grupos de reflexão. (Entrevista com Maria Lygia Quartim de Moraes).

Invisíveis à opressão militar, as feministas tornaram-se visadas pela esquerda, que logo percebeu o grande potencial dos encontros realizados 
por elas. Segundo Maria Lygia, o machismo acabou por proteger as mulheres da esquerda, pois a polícia não dava crédito à competência e à importância delas nas organizações. Dentro dos agrupamentos de esquerda, a pressão era grande por causa da dupla militância. As mulheres acabaram por ter uma participação fundamental na luta contra as ditaduras. Estavam lá e agiam, mesmo não sendo oficialmente consideradas.

Maria Lygia comenta que havia muitas diferenças entre as guerrilheiras e as feministas burguesas, como era o caso de Danda Prado, que ela conheceu em Paris durante o exílio.

Danda Prado foi para Paris em 1970, quando seu primeiro marido estava preso pelo regime militar brasileiro. Tendo sido anfitriã de Simone de Beauvoir na visita com Jean Paul Sartre ao Brasil, foi buscar com ela orientação de como chegar às feministas francesas. A indicação que teve foi para procurar primeiro uma cubana que poderia ajudá-la, já que Simone achava o feminismo de esquerda das brasileiras muito diferente do francês. As francesas estariam mais engajadas na luta feminista em si. Danda acabou agrupando algumas brasileiras exiladas que acompanhavam os maridos no exterior. ${ }^{4}$ Quando começaram a ganhar notoriedade, os maridos foram os primeiros a querer impedir as reuniões, além da direção do Partido Comunista, o chamado "Partidão", que apostou em outro grupo de mulheres não feministas, comandado em Paris por Zuleika Alambert. (Entrevista com Yolanda 'Danda' Prado). Mais tarde a própria Zuleika viria a se identificar com o feminismo.

A argentina Leonor Calvera também aponta algumas divergências entre as feministas que ficaram no país no momento do golpe e as que foram para o exílio. Em ambas as situações eram vistas como desertoras, as que foram pelas que ficaram, e as que ficaram, por terem sido "coniventes" com a ditadura. Leonor se ressente e afirma que só as burguesas puderam viajar (Entrevista com Leonor Calvera).

Muitas mulheres se fizeram feministas no exterior, em contato com as idéias e teorias que já circulavam na Europa e nos Estados Unidos. A brasileira Danda Prado pode ser situada, no período, em um dos ângulos da triangulação Europa-Estados Unidos-América do Sul. Algumas argentinas, como Dora Barrancos, vieram se exilar no Brasil durante a ditadura

4 Este tema também é abordado por Joana Maria Pedro e Cristina Scheibe Wolff (2007) 
militar. Podemos buscar compor assim um panorama de trocas culturais e políticas, possível para aquele momento.

Em todos os depoimentos das argentinas e nos da maioria das brasileiras fica claro que as feministas que tinham dinheiro estavam fora ou viajavam para conseguir material impresso lançado no exterior. Foi assim que se depararam com as leituras de Betty Friedan, Juliet Mitchell, Shulamith Firestone, Carla Lonzi, entre tantas outras que influenciaram na tomada de consciência e na organização dos grupos feministas em ambos os países. A leitura de $O$ segundo sexo, de Simone de Beauvoir (que não se considerava feminista) é tomada quase com unanimidade como o ponto de partida, mesmo no momento em que muitas ainda não se consideravam feministas. Volto a lembrar que o preconceito com esta denominação retardou, em muito, a tomada de postura de boa parte dessas mulheres.

Distante de ser um corpo homogêneo, o feminismo aparece fragmentado por hierarquias e divisões internas, como uma multiplicidade de vozes que se juntam, cada qual soando de lugares próprios, singulares, como podemos acompanhar nas entrevistas.

No artigo "A ilusão biográfica", Pierre Bourdieu (1998) mostra o risco de se olhar para uma história de vida como caminho ou sucessão de acontecimentos. Introduzo aqui a autobiografia de María Helena Oddone. Uma observação que se pode fazer é que ela utiliza algumas vezes em sua narrativa expressões que indicam uma trajetória, em expressões como "desde pequena...", gerando um efeito de previsibilidade. Assim, lá no passado já se podia perceber certas características de rebeldia que teriam seqüência na vida desta mulher, segundo seu próprio relato. Heleieth Saffioti também afirma: "Eu sempre fui rebelde!"

A vida não pode ser organizada como história, nos diz Bourdieu (1998, p. 184-5). Para ele, a preocupação com o sentido no relato pode torná-lo artificial, aproximando-o da estrutura do romance. A vida como história é uma ilusão retórica, adotada com freqüência no "falar de si", na "produção de si". O autor aconselha a análise do conjunto de relações objetivas, em que outros agentes envolvidos devem ser considerados, compondo assim o mesmo espaço dos possíveis.

Para Giovanni Levi (1998, p. 170 ss.), os historiadores devem se manter atentos à fragmentação, à variação de tempos, ao caráter contraditório e paradoxal dos pensamentos e da linguagem dos protagonistas. O objeto da descrição pode ser analisado como probabilidade, não como 
propriedade. Para ele também a coerência faz parte de uma ilusão. Aponta a complexidade das redes de relações nos grupos sociais e atenta para a definição dos indivíduos em relação aos grupos.

Observando a narrativa de María Elena Oddone, não podemos aceitar que um indivíduo tenha as características de um grupo. Ela se via como uma líder nata, mas foi expulsa de diversos grupos pelo individualismo exacerbado e falta de senso de equipe. Segundo Levi, não temos acesso aos processos de tomada de decisões, apenas aos atos, portanto as variáveis do quadro das relações dificilmente são acessadas. As memórias permitem a aproximação com as possibilidades, não com "verdades". As versões oficiais sobre os fatos criam uma ilusão de comportamentos homogêneos por parte dos grupos estudados, desconsiderando o destino individual.

Olhando para as memórias das argentinas Sara, Leonor, Mirta e María Elena, podemos perceber certos comportamentos e ações paralelos entre as duas primeiras, que se modificam em Mirta - feminista e mulher política - e se distanciam de María Elena, considerada individualista e de direita pelas outras. Todas eram feministas, todas militavam, mas cada uma à sua maneira, compondo suas redes de relações e elaborando pontos de vista, portanto modos de agir, distintos.

As memórias dessas mulheres se constituíram de experiências de vida em um contexto de repressão militar e civil. Além disso, a opressão vinha também da própria construção de gênero e sua hierarquia dentro da sociedade, motivo pelo qual se tornaram feministas. As escolhas e as ações podem ser vistas como respostas à demanda de um contexto. Suas restrições e estratégias também se orientam de acordo com as normas desse quadro mais amplo.

Alessandro Portelli (1998, p. 105) nos lembra que um único episódio pode suscitar memórias diferentes em grupos ou mesmo indivíduos que o protagonizaram. Além disso, cada pesquisa e produção escrita sobre um mesmo episódio é realizada de maneira distinta por cada pesquisador. É o que acontece quando o autor analisa trabalhos escritos sobre um mesmo tema: o fuzilamento em massa executado pelo exército alemão sobre os moradores de Civitella - um povoado italiano - durante a segunda guerra mundial. As fontes foram depoimentos gravados dos sobreviventes.

A memória aparece dividida e trespassada por ressentimentos entre grupos formados dentro do mesmo povoado. Os depoimentos apresentam 
contradições. Mais importante do que a verdade dos fatos é como o que aconteceu ficou marcado na memória da comunidade. "[...] é improvável que qualquer experiência possa ser verdadeiramente expressa”. Além disso, os narradores são mediados por estruturas, como a escolha de palavras e a construção coerente dos discursos, portanto as narrativas devem ser entendidas criticamente e contrapostas a outras. (Portelli, 1998, p. 105).

Seguindo estes argumentos, os testemunhos das feministas são colocados lado a lado, para que se tenha uma idéia mais ampla de significado nas narrativas sobre um mesmo período e episódios compartilhados por elas. Uma unanimidade que ganha destaque é o ressentimento com que olham para o movimento feminista das décadas posteriores, principalmente dos anos 80 e 90. A impressão que fica é a da busca do reconhecimento de uma origem do feminismo argentino contemporâneo naquelas primeiras ações dos anos 1970. Criticam a falta de visão das que vieram depois e o retrocesso no movimento feminista atual.

Moema Toscano também destaca os áureos tempos do feminismo no Brasil, com seu auge em 1975, quando se inicia a chamada "Década da Mulher", lançada pela Organização das Nações Unidas (ONU). Ela relembra:

Então essas passeatas dos primeiros anos do Centro (da Mulher Brasileira) eram gloriosas. Depois foram murchando. Às últimas eu já não fui. À do ano passado eu fui só pra olhar, só pra ver como tava um horror. Não conheci ninguém, ninguém tinha ficado daqueles velhos tempos. (Entevista com Moema Toscano).

Sobre esse tipo de sentimento, Portelli (1998, p. 115) questiona os depoimentos que expõem uma perspectiva de supervalorização do passado diante do presente. O passado era perfeito, se comparado aos anos que vieram depois. $\mathrm{O}$ autor atenta também para as repetições que aparecem em diversas entrevistas; elas devem ser analisadas mais demoradamente. O ressentimento com as gerações posteriores de feministas aparece como repetição nos depoimentos das brasileiras e das argentinas.

Moema Toscano nos dá elementos para refletir sobre o significado da década de 1970 para o movimento feminista dos dois países, quando relembra o auge do movimento feminista brasileiro em 1975. As argentinas começaram a se articular efetivamente a partir de 1970, com a criação 
da UFA - Unión Feminista Argentina - em 1971. Sara Torres e Leonor Calvera estiveram neste grupo. Mesmo ameaçadas por grupos para-militares, o grande momento dos encontros de mulheres argentinas em torno da causa feminista se deu entre 1970 e 1976, o ano do golpe contra o governo peronista. Em 1974 María Elena Oddone começa a editar o periódico feminista Persona. Neste momento o Brasil estava sob uma cerrada repressão política e social. Quando finalmente as brasileiras podem começar a se manifestar, com o retorno de algumas exiladas em $1975^{5}$ e com o incentivo da ONU, as reivindicações argentinas são solapadas pelo golpe que fez calar durante anos qualquer tipo de manifestação social.

Do movimento feminista dos anos 1970, fala-se muitas vezes como se fosse unificado. Já não é possível entendê-lo desta maneira, nem deixar de questionar a tentativa de se inventar uma "identidade" para ele. A multiplicidade é evidente, principalmente quando nos deparamos com um material tão variado, como os depoimentos de algumas das principais feministas do período. Os fatos foram apenas pontos de convergência, diante das mais variadas escolhas e redes de relações.

Stuart Hall, ao colocar em discussão identidade (sempre "sob rasura") e identificação, pode contribuir com o propósito deste trabalho no sentido de compreender que a identificação nunca encontra uma totalidade, mas está sempre em construção. "[...] ela envolve um trabalho discursivo, o fechamento e a marcação de fronteiras simbólicas” (Hall, 2000, p. 106). A identidade para Hall é utilizada como conceito estratégico e posicional, ela se refere àquilo que nos tornamos, é construída dentro do discurso, não fora dele. Portanto, a subjetividade de cada uma das feministas entrevistadas obviamente se constituiu no interior dos discursos feministas, com a apropriação de vários elementos desses discursos na composição das singularidades. Não é à toa que se reivindicava uma "identidade" feminista como demarcação de um espaço de poder. Analisando o pensamento de Michel Foucault, Hall nos diz que "o corpo tem funcionado como o significante da condensação das subjetividades no indivíduo" (Idem, p. 121). Diante de uma "identificação sexuada", muitas mulheres tiveram que se posicionar.

5 Lembro que a maioria das exiladas e dos exilados políticos começam a retornar ao Brasil depois da anistia, em 1979. Na Argentina, o retorno acontece somente após 1983, com o fim da ditadura. 
1975 - ano que inaugura a Década da Mulher - marca o primeiro encontro feminista no Brasil, realizado na Associação Brasileira de Imprensa, no Rio de Janeiro. Muitas mulheres se encontraram e muitas aderiram ao movimento feminista naquele momento. Entre elas estava Maria do Espírito Santo Tavares dos Santos - a Santinha - vinda do Maranhão, formada em medicina no Rio de Janeiro. Ao lado de Moema Toscano, Heloneida Studart, Fani Tabak, Leila Linhares e Jacqueline Pitanguy, formou a primeira entidade voltada para as mulheres - o Centro da Mulher Brasileira, que atuou até 2003 (Entrevista com Maria do Espírito Santo Tavares dos Santos 'Santinha').

Santinha e Moema consideravam-se feministas de ação, atuando junto a mulheres de bairros pobres do Rio de Janeiro, com programas de saúde e conscientização. Ao contrário de Moema, que apenas era simpatizante, Santinha entrou muito cedo no "Partidão". Sua primeira desavença com a direção se deu quando percebeu que era tratada como um instrumento para levar mais mulheres à adesão ao Partido Comunista, que aproveitava sua atuação feminista. A resposta de Santinha deixa clara sua opção: “[...] eu coloquei em uma reunião do Partidão: 'essa tarefa eu não quero mais". Como ela, aos poucos as mulheres que exerciam a dupla militância foram entendendo que a questão da desigualdade superava as questões políticas.

Sara Torres também se considera e é considerada uma feminista de ação. Lá estava ela, no cenário dos tempranos 70 , panfletando nas ruas de Buenos Aires, recolhendo assinaturas ou produzindo e atuando nos filmes de cunho feminista da cineasta María Luisa Bemberg. Apesar da postura totalmente de esquerda, ela fazia parte do grupo que não queria mesclar política ao feminismo, pois ressalta que havia mulheres de todas as classes sociais dentro dos grupos feministas aos quais pertenceu e que mesmo as mais privilegiadas socialmente, como María Luisa, também sofriam a opressão por serem mulheres (Entrevista com Sara Torres).

Sara critica María Elena Oddone pela falta de senso coletivo, pulando à frente das câmeras da imprensa com cartazes, deixando para trás as colegas organizadoras das manifestações, e expondo o movimento feminista com seus ideais pessoais; além disso, seu engajamento político era tido como de direita. María Elena se via como uma líder-nata; expulsa de vários grupos, diz em sua autobiografia não compreender porque era injustiçada pelas companheiras (Oddone, 2001). 
Cada depoimento se faz necessário ao sentido de compreender que um grupo se compõe também da singularidade e das desavenças entre os seus membros. As redes de relações nos levam às tomadas de decisões, que levam aos fatos. As transgressões aos acordos e as rupturas entre os indivíduos arrematam a composição do quadro e por vezes lançam um movimento contrário, dentro de um conjunto que, visto à distância, pode parecer estável e unificado.

Nada aparece sobre o movimento feminista em livros de autores argentinos e brasileiros que abordam as ditaduras militares nos dois países. O que se pode encontrar são os periódicos e livros publicados pelas feministas denunciando sua situação e mostrando sua atuação social e política.

A historiografia argentina, com exceção da militância feminista acadêmica, desconsidera a atuação do movimento no início dos anos 1970, assim como durante a última ditadura militar.

Nas entrevistas com as militantes do período, elas são unânimes ao afirmar que recebiam ameaças de uma temida organização denominada Três A. Este grupo da extrema direita radical, formado por oficiais de polícia e militares aposentados e na ativa, atuava efetiva e sistematicamente antes do golpe militar. A Alianza Anticomunista Argentina teve seu auge entre 1973 e 1976. A organização clandestina contava com apoio logístico e financeiro de setores da extrema direita do governo. Foi responsável por mais de 900 assassinatos de pessoas consideradas subversivas e publicava listas com os nomes de suas próximas vítimas (Novaro e Palermo, 2006, p. 81).

Mirta Henault rompeu com muitas feministas, pois "não podia deixar de ser marxista". Recebeu carta de ameaça dos Três A, por ser de esquerda e ainda participar de ações da militância feminista. Decidiu abandonar o partidarismo político e seguiu participando ativamente de pesquisas e publicações feministas, até os dias de hoje.

Leonor Calvera conta que era de família anarquista, portanto, também visada pelos Três A e depois pelo regime militar. Ela e as companheiras eram forçadas a queimar livros comprometedores, suas fontes de memória e saber. Tudo era feito às escondidas, como também nos lembra Sara Torres. Quando se reuniam, as feministas decoravam a mesma história, de alguma celebração que faziam na casa de uma amiga, para escapar aos flagrantes da sangrenta ditadura militar argentina.

De acordo com Marcos Novaro e Vicente Palermo (2006, p. 83), a subversão era " $[. .$.$] un enemigo social, político e ideológico con muchos$ 
rostros y brazos, que actuaba en distintos terrenos y con variadas formas organizativas y métodos." O feminismo era um desses rostos, considerados perigosos, podendo ser visto como um dos braços do comunismo, disfarçado. Nele havia muitas socialistas, na maioria trotskistas (Brujas, 2006, p. 64).

Se feministas recebiam ameaças de morte - como as entrevistadas e a autobiografada argentinas a que me refiro -, é porque eram vistas como subversivas. Se não aparecem nos registros da historiografia oficial, é porque eram desconsideradas como grupo organizado e de esquerda, possivelmente por não terem um significado social e político na sua condição de mulheres.

O mesmo acontece com a historiografia brasileira, que anula o movimento feminista como movimento social e político, relegando-o à uma condição abjeta. Em um dos principais livros da atualidade que comparam Brasil e Argentina, Boris Fausto e Fernando Devoto não dedicam nenhuma das mais de quinhentas páginas de seu livro à luta e às manifestações das feministas no período das mencionadas ditaduras (Fausto e Devoto, 2005).

Em evidência, podemos encontrar mais facilmente os movimentos de mães - no Brasil pela anistia e na Argentina pelos filhos desaparecidos - do que a reivindicação por direitos justos e iguais. As Madres de la Plaza de Mayo abalaram a ditadura argentina; tinham voz porque eram mães, assim como as do Movimento Feminino pela Anistia, organizado no Brasil por Terezinha Zerbini. O que se permitia ouvir eram essas outras reivindicações, justas, porém socialmente naturalizadas e aceitas.

Maria Lygia Quartim de Moraes também fala sobre uma carta de ameaça enviada pela $\mathrm{AAB}$ - Aliança Anticomunista Brasileira - que dizia que a proteção com que ela contava pelos bons relacionamentos da família poderia acabar: "[...] você tem uma filha né, cuidado com a sua filha, entende, era um negócio assim. Eu sentei e falei, caramba!"

Silvia Salvatici (2005, p. 35) mostra que as experiências das mulheres foram percebidas e reconhecidas como diferentes da experiência masculina, o que permitiu refletir sobre a fragmentação da experiência humana em realidades múltiplas e marcadas, cada qual por suas especificidades.

Quando se opta por trabalhar com um tema, a própria escolha já demonstra qual é o interesse do historiador. Sem dúvida a memória é sempre suspeita, mas suspeito também é o procedimento de quem conduz a 
pesquisa. $\mathrm{O}$ autor de uma entrevista é um filtro, que está ali para racionalizar e conduzir uma conversa que se dá em meio a tristezas, euforias, rancores ou mesmo lágrimas. As emoções que impregnam uma entrevista também devem ser analisadas na hora de trabalhar com o material como documento. Distorções, negociações e escolhas compõem o desafio da interpretação.

Verena Alberti alerta para a tentação que pode rondar os historiadores no sentido de quererem construir memórias, enquanto sua tarefa é a de estudar a sua constituição. Diferentemente da autobiografia, ela apresenta a entrevista como objeto de autoria de dois autores: o entrevistado e o entrevistador. "Mesmo que o entrevistador fale pouco, [...] a entrevista que ele conduz é parte de seu próprio relato - científico, acadêmico, político, etc. - sobre ações passadas, e também suas ações" (Alberti, 2005, p. 169).

Quando conduzimos uma entrevista, por mais que tenhamos um roteiro pré-elaborado, não podemos nos furtar a corresponder também às expectativas do entrevistado quando, por exemplo, ele desvia a resposta da pergunta ou do próprio tema, não deixa brechas de retorno imediato e demanda um acompanhamento de raciocínio.

Experimentei isso na entrevista com Leonor Calvera, que em muitos momentos guinava o assunto e seguia falando sobre sua experiência no presente. Mesmo este desvio é passível de uma observação mais detalhada. O que ela queria com isso? Mostrar que seu afastamento atual das atividades feministas não significava o afastamento de atividades intelectuais e do próprio feminismo? Leonor fazia questão de direcionar algumas respostas para seus trabalhos em andamento, não mais de militância, mas de grande capacidade intelectual, ainda sobre temas que se referem às mulheres.

Seja como for, os silêncios ou os excessos fazem parte das entrevistas e podem ser ouvidos com mais atenção já que, segundo Alberti, o depoimento do entrevistado depende também de como ele percebe o entrevistador.

\section{Considerações finais}

Partindo de tão variados pontos de vista, fica fácil compreender que não houve nos dois países, e provavelmente em nenhum outro da América 
Latina, um único movimento feminista, mas vários movimentos, de vários grupos, com bases ideológicas e filosóficas distintas.

Podemos pensar esses testemunhos como relatos de vida, ou parte dela, que sofrem influências constantes e variadas, permeados pela individualidade, por lapsos ou excessos da memória, além de certezas e enganos, próprios das lembranças humanas. Portanto, os relatos devem ser devidamente problematizados, para que possam auxiliar na composição de questões para a historiografia.

Quanto à identificação com o feminismo, este é o ponto central que podemos destacar em todos os depoimentos. Os temas tratados nos periódicos publicados pelos grupos feministas brasileiros e argentinos eram muito semelhantes, as autoras mencionadas nas entrevistas - Simone de Beauvoir, Betty Friedan, Juliet Mitchell, Shulamith Firestone, Carla Lonzi e outras - eram lidas pela maioria delas. As relações que fazem com a teoria "importada" da Europa e dos Estados Unidos são bastante semelhantes, o que nos possibilita pensar na efetividade de uma triangulação, muito mais no sentido vertical, de "beber da fonte" da teoria européia e estadunidense, do que no sentido horizontal, de trocas entre as feministas brasileiras e argentinas. Certamente algumas trocas ocorreram, mas o principal foco das feministas sul-americanas estava em outro hemisfério.

Cláudia de Lima Costa contribui com a discussão sobre o trânsito transnacional de teorias e conceitos, observando "relações de poder e assimetrias entre linguagens, regiões e povos" (Costa, 2004, p. 188). Para ela, o alto nível de abstração de algumas teorias rompe as barreiras dos contextos, mas as teorias feministas compreendem diferentes níveis de abstração. Analisando a situação das Américas, afirma que os discursos e práticas encontram bloqueios, ao mesmo tempo em que as diferentes historiografias excluem sujeitos e subjetividades. Supondo um imperialismo conceitual e intelectual, os "conhecimentos subalternos" são rejeitados. Ou seja, há o primeiro impedimento das mulheres como sujeito na historiografia e o segundo impedimento das teorias feministas latino-americanas, consideradas de periferia, diante da intelectualidade feminista dos países considerados de centro. Para a autora,

Diante da intensa migração de conceitos e valores que acompanham o trânsito de textos e teorias, freqüentemente acontece que um conceito com potencial para uma ruptura política e 
epistemológica, em um determinado contexto, torna-se despolitizado quando transferido para outro contexto (Costa, 1994, p. 191).

Isso certamente aconteceu no momento em que os discursos das feministas políticas de esquerda marxista, sul-americanas, entraram em contato com as francesas, como nos conta Danda Prado. Cláudia de Lima Costa aponta que isso também ocorria no contexto norte-americano, onde a luta de classes não ecoava, como discurso vazio que era naquele lugar.

A especificidade sul-americana diante do cenário feminista mundial foi a repressão, além do gênero, também dos governos da direita militar. O feminismo sul-americano nasce nesse paradoxo: de um lado a visão externa e a influência eurocêntrica; do outro, a ditadura militar dentro dos países, fazendo calar as manifestações.

Maria do Espírito Santo Tavares dos Santos - Santinha - nos ajuda a entender melhor essa especificidade com seu pensamento feminista tipicamente brasileiro: "[...] a leitura, a sensação, eu até coloquei isso discutindo com grupos menores, que eu tinha é que o que Simone de Beauvoir colocava, no livro maravilhoso, era uma coisa de lá, e aqui a gente tinha outra coisa; feminismo aqui é outra coisa, neguinha!"

Portanto, se há uma triangulação, ela é feita num sentido vertical, onde o vértice "inferior" geográfico do triângulo aparece como receptor das discussões teóricas e das práticas que se dão em outro hemisfério. $\mathrm{O}$ feminismo sul-americano teve que "se virar", de acordo com suas próprias possibilidades e sua resistência.

Outra questão relevante é a da invisibilidade. Muitas dessas mulheres, argentinas e brasileiras, lutaram, militaram, foram ameaçadas como subversivas, tiveram que se esconder, pois seus nomes constavam nas listas de extermínio, mas não existiram para a historiografia dos dois países. Reconhecido como a grande revolução do fim do século XX por autores comentados, como Eric Hobsbawm e Stuart Hall, o movimento feminista é abjeto no contexto ainda machista dos países sul-americanos.

Observando os testemunhos das feministas dos anos 70, é possível perceber que referências comuns perpassam o relato de cada uma delas: livros, eventos, militância... A maioria tomou o feminismo como norteador de suas atividades, mesmo depois de tantos anos passados. Olhando 
mais de perto, as particularidades tornam-se evidentes, o que enriquece em muito as possibilidades levantadas a partir de pesquisas sobre o tema.

A permanência, no contexto mais amplo, fica por conta da ditadura do gênero, que não foi abolida nos anos 1980 com os regimes militares. O movimento feminista passou a ser um esforço cotidiano, onde cada mulher tenta ampliar seus espaços de atuação e reconhecimento, dentro de uma sociedade que ainda precisa de "identidades", com raras noções daquilo que constitui a igualdade. Isso tudo, quarenta anos depois...

\section{Entrevistas}

Heleieth Saffioti - São Paulo, 02.08.2005, por Joana Maria Pedro.

Leonor Calvera - Buenos Aires, 01.03.2007, por Ana Maria Veiga.

Maria do Espírito Santo Tavares dos Santos - Rio de Janeiro, 14.02.2005, por Roselane Neckel.

Maria Lygia Quartim de Moraes - Florianópolis, 28.03.2007, por Joana Maria Pedro e Cristina Scheibe Wolff.

Mirta Henault - Buenos Aires, 23.02.2007, por Ana Maria Veiga.

Moema Toscano - Rio de Janeiro, 16.02.2005, por Roselane Neckel.

Sara Torres - Buenos Aires, 01.03.2007, por Ana Maria Veiga.

Yolanda (Danda) Prado - São Paulo, 05.08.2005, por Joana Maria Pedro.

\section{Referências Bibliográficas}

ALBERTI, Verena. Histórias dentro da História. In: PINSKY, Carla Bassanezi (org.). Fontes Históricas. São Paulo: Contexto, 2005, p. 155-202.

BOURDIEU, Pierre. A ilusão biográfica. In: FERREIRA, Marieta de Moraes; AMADO, Janaína (Org.). Usos \& Abusos da História Oral. $2^{\mathrm{a}}$ ed. Rio de Janeiro: Fundação Getúlio Vargas, 1998, p. 183-191.

BRUJAS Publicación Feminista, Año 25, N. 32. Buenos Aires: ATEM, Octubre 2006.

COSTA, Cláudia de Lima. Feminismo, tradução, transnacionalismo. In: COSTA, C. L. e SCHMIDT, Simone (Org.). Poéticas e políticas feministas. Florianópolis: Mulheres, 2004

FAUSTO, Boris e DEVOTO, Fernando J. Brasil e Argentina: um ensaio de história comparada (1850 - 2002). $2^{\text {a }}$ ed. São Paulo: Editora 34, 2005.

FERREIRA, Marieta de Moraes; AMADO, Janaína (Org.). Usos \& Abusos da História Oral. $2^{\text {a }}$ 
ed. Rio de Janeiro: Fundação Getúlio Vargas, 1998.

FERREIRA, Marieta de Moraes; FERNANDES, Tania M.; ALBERTI, Verena (orgs.). História Oral: desafios para o século XXI. Rio de Janeiro: Fundação Oswaldo Cruz / FGV / CPDOC, 2000.

HALL, Stuart. Quem precisa de identidade? In. SILVA, Tomaz Tadeu. Identidade e diferençaa perspectiva dos Estudos Culturais. Petrópolis: Vozes, 2000, p. 103-133.

HENAUlT, Mirta; MORTON, Peggy; LARGUIA, Isabel. Las mujeres dicen basta. Buenos Aires: Nueva Mujer, 1970.

LEVI, Giovanni. Usos da biografia. In. FERREIRA, Marieta de Moraes; AMADO, Janaína (Org.). Usos \& Abusos da História Oral. 2a ed. Rio de Janeiro: Fundação Getúlio Vargas, 1998.

NOVARO, Marcos e PALERMO, Vicente. La dictadura militar 1976/1983 - del golpe de Estado a la restauración democrática. Col. Historia Argentina, vol. 9. Buenos Aires: Paidós, 2006.

ODDONE, María Elena. La pasión por la libertad-memórias de una feminista. Buenos Aires: Ediciones Colihue Mimbipa, 2001.

PEDRO, Joana Maria. Os sentimentos do feminismo. In: ERTZOGUE, Marina Haizenreder e PARENTE, Temis Gomes (Org.). História e sensibilidade. Brasília: Paralelo 15, 2006.

e WOLFF, Cristina Scheibe. Nosotras e Círculo de Mulheres Brasileiras em Paris: feminismo tropical na França. Revista ArtCultura, Jan. Jun. 2007, (no prelo).

PORTELLI, Alessandro, O massacre de Civitella Val de Chiana (Toscana, 29 de junho de 1944): mito e política, luto e senso comum. In. FERREIRA, Marieta de Moraes; AMADO, Janaína. Usos \& Abusos da História Oral. $2^{\mathrm{a}}$ ed. Rio de Janeiro: Fundação Getúlio Vargas, 1998.

SAFFIOTI, Heleieth Iara Bongiovani. A mulher na sociedade de classes: mito e realidade. Petrópolis: Vozes, 1979.

SALVATICI, Silvia. Memórias de gênero: reflexões sobre a história oral de mulheres. In. Associação Brasileira de História Oral. História Oral. Vol.8, n 1, Recife: CNPq, 2005.

Resumo: Este artigo busca compreender como se davam as relações entre feministas brasileiras e argentinas no período pós-1968 e as redes de circulação de informações e teorias que se criavam com a leitura de materiais nacionais e estrangeiros; e procura, nos depoimentos das protagonistas desses primeiros anos, elementos para pensar o feminismo como movimento, nas suas continuidades e rupturas. O período proposto vai até o final da década de 70, passando por pontos de convergência, mas também de distanciamento entre os dois países. Afinal, quais as semelhanças e as diferenças na constituição dos feminismos no Brasil e na Argentina? Como se constituiu esse novo sujeito político e qual a sua representatividade social nos dois países? As possíveis respostas para estas questões são alcançadas com o suporte da história oral e o aparato das discussões sobre identidade e identificação. 
Palavras-chave: Feminismo; História Oral, Brasil, Argentina

Memories of Feminism: repression and invisibility (Brazil and Argentina after 1968)

Abstract: This article wants to comprehend how relations among Brazilian and Argentine feminists were made in the period of time after 1968 and how the information and theories circulation net takes form, with the reading of national and foreigner writings. It searches in the memories of these feminists that acted at those early years elements to think about feminism as a movement, with its continuities and ruptures. The purposed period of time goes until the end of the 70 's, passing through convergent points but also through the distant ones between the two analyzed countries. What are the similarities and the differences in the Brazilian and Argentine feminism constitution? How this new politic subject was constructed and what is its social representativity in both countries? The possible answers for these questions are reached with the Oral History support and the identity and identification discussions.

Keywords: Feminism; Oral History; Brazil; Argentina. 